\title{
The Last Planner System Style of Planning: Its Basis in Learning Theory
}

\author{
Bo Terje Kalsaas \\ Associate Professor, Department of Working Life and Innovation, University of Agder at Grimstad, E-mail: \\ bo.t.kalsaas@uia.no
}

Project and Production Management

Received October 18, 2011; received revision November 14, 2011; accepted November 27, 2011

Available online December 23, 2011

\begin{abstract}
The objective of this article is to contribute to creating a better understanding of the Last Planner System (LPS) - which is associated with Lean Construction - in the light of the learning processes at the basis of knowledge development, and of change and innovation. Founded on a theoretical discussion, three research questions are asked, namely: In what ways can the LPS be expected to alter the learning arenas compared to conventional project management in construction; according to learning theory, what are the main challenges associated with implementing the LPS; and, finally, what kind of learning can be linked to an implemented LPS that functions as intended? The implementation of the LPS is shown to require substantial changes to the technical-organisational learning arena. In order for the implementation to be successful, the work identity has to alter on the individual level so that an overlap occurs with the new work practices prescribed by the LPS. The LPS has an inbuilt experiential learning cycle, and provides a good starting point for single-loop learning, as well as for simple forms of double-loop learning ("routinized learning capability"). However, it is argued that the LPS understood as experiential learning has clear limitations with regard to "evolutionary learning capability". This is amplified by the context project organisation provides. In terms of theoretical implications, this article promotes an understanding of the planning process informed by the theory describing it as an experiential learning cycle. The conceptualisation which separates the LPS from conventional production control theory is critiqued. Finally, it is argued that an understanding of the LPS grounded in learning theory will improve the possibilities for successful implementation and maximise the learning effects.
\end{abstract}

Keywords: Last planner system, learning, implementation.

\section{Introduction}

The Last Planner System of Production ControlTM (LPS) (Ballard, 2000; Koskela and Ballard, 2006a) has a very central place within Lean Construction, and can be witnessed in the shape of a concrete set of guidelines implemented in many corners of the world over the past 10-15 years. Note that The Last Planner System is a trademark of the Lean Construction Institute. The aim is to achieve greater control and predictability in construction work compared to that which is offered by conventional project management, known as the critical path method (CPM). Brodetskaia et al. (2011) argue that the scope of the CPM is generally restricted to master scheduling. Although being an effective contract management tool for clients, it does not provide general contractors with a weekly or daily production control tool.

The traditional project management practices and their underlying theory are challenged by several scholars in the lean construction community. Koskela and Howell (2002) and Koskela and Ballard (2006) describe conventional production control as the "thermostat model", and LPS as the "scientific experimentation" model. Moreover, they argue that project management should be based on theories of production, not of economics (Koskela and Ballard, 2006b).

The LPS is based on extensive cooperation between different contractors and subcontractors who commit to coordinating their activities in increasing detail as the practical implementation approaches. Furthermore, in hindsight the last and most detailed production plan is evaluated, and experiences with regard to what caused divergence between planned and actual implementation (PPC: percentage planned completed) are reported back to the collaboration partners. The LPS can be regarded as a practical organisation of construction site production inspired by, or consistent with, central aspects of the thinking associated with supply chain management (SCM) in construction - according to which a series of legally independent companies need to collaborate in one way or the other in order for construction projects to be realised.

The LPS originated as a very practical approach that has proved to function better in practice than conventional project management (Koskela and Ballard, 2006b). Founded on a realisation that practical methods and tools 
are based, implicitly or explicitly, on theories that are not separate and distant from the actual practices, but embodied by them, theory underpinning the LPS has later been developed and is currently subject to further development, together with the practical aspects of the LPS approach (Koskela and Ballard, 2006b; Macomber and Howell, 2003; Howell et al., 2004; Macomber et al., 2005; Kalsaas and Sacks, 2011).

Several scholars point out the learning aspects tied to the LPS, particularly in terms of its focus on evaluation of the production plans (e.g. Ballard, 2000; Rooke, 2005; Koskela et al., 2010). However, the learning aspect as such is not problematised in any of these works, except to some extent in Rooke (2005). The lean construction literature also generally fails to do so; see for example Ko et al. (2011) and Bresnen (2009). The title in Bresnen's work refers to knowledge, learning and innovation, but the actual article is primarily a summative assessment of learning, without any problematisation or examination of the actual learning process. Rooke (2005), on the other hand, discusses the implications of some educational and management learning theories for the implementation of lean construction. He links different learning cycle theories to the LPS, and reviews some management techniques that can be used when adopting techniques such as the LPS.

The objective of this work is, firstly, to relate the LPS to different aspects of experiential learning, in which learning is seen as "the process whereby knowledge is created through the transformation of experience" (Kolb, 1984: 34), and, as part of this, to link experiential learning to workplace learning. Note that this study is part of the research project "Involverende planlegging" ("Inclusive planning”). It is partially financed by the Norwegian Research Council, but the owner of the research project is Veidekke. Secondly, to relate the implementation of the LPS to learning theory which focuses on workplace learning (Illeris, 2009), seeking, among other things, to help create deeper insight into the challenges that must be overcome in order to bring about change, thus fortifying the awareness required to create such change.

The validity of the method is based on analytical generalisation and the theoretically informed case study approach (Yin, 1989). This method allows in-depth exploration of questions of "how" and "why"- which means that the study represents a partial test of the theory, and may serve as a basis for modifying it. This is how theoretically informed case studies make their contribution to research. Based on a review and discussion of learning theory, theoretically informed research questions are formulated. These questions are then used in the analysis of the LPS.

The empirical material, or the case, is the Last Planner System (LPS), and the task is to explore how we may understand and evaluate the LPS on the basis of learning theory. This can also be understood as uncovering the indirect theoretical foundations of the LPS with regard to learning.

The next section outlines the contents of the Last Planner System (LPS). This is followed by a discussion of the experiential learning theory, illustrated with examples from its implications for the work processes of architects and carpenters in relation to building projects. Workplace learning theory; production control in lean construction, critiques of experiential learning; and learning loops are each addressed separately before the theories are condensed and three theoretically oriented research questions are defined. These questions are then used to analyse the LPS before, finally, concluding answers to the research questions are offered.

\section{The Last Planner System of Production Control}

The Last Planner System (LPS) is a practical approach in which construction managers and team leaders collaborate to prepare work plans that can be implemented with a high degree of reliability, thus improving work stability and predictability. As originally formulated by Ballard (2000), the LPS seeks to achieve "coordination by plan" (Kalsaas and Sacks, 2011). It differs from traditional planning in that it assumes that the uncertainty of making predictions for the point at which all constraints are out of the way so that work can commence can only be removed in the final instance by the team leader responsible for providing the labour needed for any given task. This is usually the trade crew manager or leader, who is termed the "last planner".

In an attempt to clarify what the LSP involves, Koskela et al. (2010) described its implementation as consisting of five steps:

- Preparation of a master schedule, reflecting the major project milestones.

- Phase planning, which commonly involves using reverse-phase scheduling - i.e. working backwards from the desired delivery date (milestones), tasks are scheduled in reverse order, allowing them to be performed at the "last responsible moment", thus minimising unnecessary accumulation of work in progress.

- Preparation of a lookahead plan for the medium-term future. The state of the preconditions must be evaluated for all of the tasks in the lookahead plan (usually using checklists based on the seven groups of task preconditions) (Koskela, 2000). Efforts must be made to remove the constraints, and any tasks whose constraints have been removed should be put on a list called the 'workable backlog.'

- Preparation of a weekly work plan in consultation with the last planners, which involves negotiations with all parties to achieve a plan that is considered feasible and which has everyone's commitment. This is usually done in a "Last Planner" meeting, which brings the different trade managers together to coordinate their activities over the following week. This meeting is different to standard planning meetings for the week ahead in that instead of management dictating a pre-conceived plan, the squad leader select the tasks to be performed using a strict "can be done" filter in their selection. This ensures that only "mature" tasks (from the workable backlog) are scheduled. The method avoids assignment of tasks that "ought to" be carried out according to the lookahead or master plans, but which are hampered by unresolved constraints.

- Monitoring of the execution and preparation of a report of the percentage planned completed (PPC) in order to learn about planning failures and to institute continuous improvement.

Macomber et al. (2005) address the need to include daily stand-up meetings into the LPS. Such meetings are also frequently used in lean production and Total Quality 
Management (TQM) for mutual adjustment purposes and information exchange across trades and functions, and in this context they are commonly known as "morning meetings"; see for example Kalsaas and Jakobsen (2009). Furthermore, Kalsaas and Sacks (2011) suggest that the LPS should include a strategy for implementation based on the nature (sequential or reciprocal) of the interdependence between tasks.

\section{Concepts of Learning}

\subsection{Experience-Based Learning Theory}

Kolb (1984) emphasises that learning is a process rather than a result, and furthermore, that knowledge is a transformation process continuously created and recreated - not an independent entity that can be acquired or transmitted. Knowledge creation occurs at all levels, from the most advanced forms of scientific research to the child's discovery that being stung by a wasp is a painful experience that is best avoided in the future.

"Knowledge" is the outcome of a transaction between social knowledge and personal knowledge. Social knowledge (Dewey, 1938) is the civilised objective accumulation of previous human cultural experiences, whereas personal knowledge is the accumulation of the individual person's subjective life experiences. Knowledge results, then, from the transaction between these objective and subjective experiences in a process called learning. Hence, according to Kolb, to understand knowledge, we must understand the psychology of the learning process; and to understand learning, we must understand the epistemology - the origins, nature, methods, and limits - of knowledge. Kolb draws heavily on Piaget (1970a) when he emphasises the need for epistemological understanding.

Kolb points out that learning is often obstructed by the fact that conflicting assumptions about the nature of knowledge and truth are held by teacher and learner - that is, by conflicting epistemological assumptions. He emphasises that each topic to be taught requires its own approach, while also underlining the crucial importance of the teacher's skills in empathic listening.

Furthermore, Kolb builds above all on Lewin (1951), Dewey $(1910,1934,1938,1958)$ and Piaget (1951, 1968, 1970a, 1970b, 1971, 1978) when developing this wellknown model for experiential learning. In this model, the process and structure of learning are depicted as a fourstage cycle involving four adaptive learning modes. These evolve from 1) concrete experience; 2) reflective observation; 3) abstract conceptualisation; and 4) active experimentation. This learning cycle can be understood as a continuous spiral where the different cycles of adaptive learning are repeated in order to allow for further learning. An onion can be used as a metaphor for this process each layer representing a level of knowledge.

Combining the four learning modes, Kolb divides them into two dimensions, where they represent pairs of dialectically opposed adaptive orientations - namely 1) concrete experience versus abstract conceptualisation; and 2) active experimentation versus reflective observation. The abstract - concrete dialectic is one of "prehension". Prehension is a concept invented by Kolb to describe the representation of two different and opposed processes of grasping or taking hold of experience in the world, either by relying on conceptual interpretation and symbolic representation - a process described by Kolb as "comprehension" - or by relying on the tangible, felt qualities of immediate experience, which he describes as "apprehension". The active - reflective dialectic is seen as one of transmission, representing two opposed ways of transforming what has been grasped through the prehension of experience, either through internal reflection - a process Kolb describes as “intention" - or through active external manipulation of the external world - described as "extension". There is thus a clear "division of labour" between these two dimensions of learning, namely that of capturing or grasping experience, and of ensuring that what is grasped is transported to the level where it is translated into internal understanding or external action.

\subsubsection{Experiential Learning Discussed in Relation to Construction Work}

An analysis based on learning theory of the processes involved the work of architects and carpenters is offered in order to show the relevance of the experiential learning theory in relation to construction work.

When an architect is asked to design a unique building, she will initially put a great deal of work into sketches to translate the client's wishes and goals into something that can be developed further in several rounds. It is conceivable that in order thus to translate the owner's programme and wishes, there may exist a need to learn how to understand, and how to improve the understanding, of these wishes; in other words, how to transform programme and wishes via intention. We can conceptualise it as the inner understanding being translated into sketches and drawings. Here, the preparation of sketches and drawings constitutes abstract conceptualisation, not active experimentation, as the work of translating the inner understanding into drawings and an abstract formal language - the nature of a sketch or drawing per se - can be regarded as a form of abstract work and as such as a matter of grasping via the process of comprehension. One might be led to believe that drawings are a materialisation of "concrete experience" in Kolb's experiential learning circle - and in a sense they are, but drawings can only be touched and sensed as paper or as a computer monitor. In order to interpret the content, grasping via comprehension is needed. This is assumed to happen fairly simultaneously to reflections and the development of a new inner understanding both by the client and the architect. In this case we are dealing with a process of experiential learning which includes almost no concrete experience prior to the start of the construction work. To assist the process of comprehension, the architect may make a 3D model to visualise her abstract conceptualisation of the construction project. Even if the model is physical, however, it is still an abstraction, as the model is a simplification of reality; but it does make it considerably easier to grasp the form of a building or building complex compared to the impression given by $2 \mathrm{D}$ drawings. An intermediate model is building information modelling (BIM).

At a somewhat later stage, various engineering trades need to be involved, and the building becomes the subject of corresponding experiential learning processes (intention - comprehension) until room plans have been prepared. At this stage, the end users may enter the experiential learning process to influence the details of the end product. 
The carpenter has probably completed vocational training and will have varying amounts of carpentry work experience. The broader his experience, the better he can be expected to cope with new situations. He will tend to start by examining drawings, which can be understood as grasping the real world, and via comprehension he works out how to translate what are often two-dimensional drawings into the practical work that needs to be done. The drawings are often incomplete, and he must therefore use his experience to adapt the implementation of the construction design. In the process of interpreting drawings and translating them into implementation he may choose to discuss his interpretation with colleagues, and with a squad foreman, if there is one. In this respect we also see that there are elements of interaction between abstract conceptualisation and reflective observation, with acquisition of insight and understanding through intention. We therefore see in this example, too, that we do not necessarily follow the full circular idea of Kolb's concept; but we can understand this as merely being a matter of several rounds of abstract conceptualisation and reflection, back and forth, before progression to the next step. Execution of the task or tasks represents the active experimentation in this picture, which is where knowledge acquired through intention and comprehension is transformed via extension. When the tasks have been carried out, we are left with concrete experiences, which we then interpret via apprehension, and which again, via reflective observation, can provide us with corrective knowledge that leads to improvements in the execution of the construction process (active experimentation), not least if this process involves repetitive tasks. The carpenter interprets drawings whose nature is that they are abstractions, but usually does not perform any abstract tasks beyond this interpretation of ready-made drawings, unlike for example an engineer. In the carpenter's work, the abstract dimension is therefore limited, whereas active experimentation and concrete experience are all the more significant. Reflective observation can also be expected to play a greater role than that of abstract conceptualisation in his learning process.

\subsection{Workplace Learning}

Whereas Kolb's model is primarily a model for individual learning processes, Illeris' (2009) model, expanding on the works of Jørgensen and Warring (2002) and Bottrup (2001), helps integrate an understanding of individual learning into an understanding of learning in working life. For workplace learning, Jørgensen and Warring (2002) have developed a model based on the concepts of learning environment and learning progress, where learning is seen as taking place in the intersection between the learning environment of the workplace and the learning progress of the employees. A distinction is made between the technical-organisational learning environment and the social learning environment. The technical-organisational aspect is constituted by the material conditions tied to technology and to the way the work is organised, which may, for example, facilitate or limit work variation, and thus impact on the possibilities for learning. The work community and social interaction constitute the social learning environment. Learning progress is linked to each employee's background and stage of life, as well as to his or her capacity to be open to and benefit from learning. Learning takes place in a dynamic interaction between the learning environment and the individual's learning progress.
Illeris (2009) divides the technical-organisational learning environment into six categories: 1) division of tasks/work; 2) work content; 3) scope for decision-making; 4) scope for using one's qualifications; 5) scope for social interaction; and, 6) work strain. A rigid division of work can undermine the individual's perception of the work as meaningful (Taylorism). Work content is linked to the work's social significance and to its significance for the individual (learning progress). What seems meaningless to one person may seem very meaningful to another, depending on their learning progress. Participating in the production of something that is perceived as good and useful can be a source of great personal satisfaction, and such involvement can be an important driving force in workplace learning processes. Illeris points out that coping with the contradictions between quality and quantity requirements associated with factory work can also amount to an individual and collective learning process. The ways in which employees learn to handle such contradictions are connected to the norms of the work community, but this connection is not a deterministic one. The scope for deciding over one's own work is connected to the style of leadership (dialogue versus orders from above) and to the organisational structure (flat structure and decentralised decisions versus hierarchical, bureaucratic structure).

The scope for using personal qualifications in the work depends on technological factors and the division of labour. When the employees discuss, reflect on, and exchange experiences and ideas with each other, learning takes the shape of a social process. Illeris points out that the opposing ideas and interests which emerge in the encounter between different trades or professions can create fertile learning environments; however, they can also help consolidate mutual myths and images that place the other party in the role of being an opponent. Technological conditions are very important for the scope for social interaction and for the social learning environment. Work performance pressures (speed and intensity) can hamper learning because they interfere with the time or physiological/mental energy needed in order for learning, development, experimentation and trying out of new ideas to take place.

Based on Botterup (2001), this part of the model can be expanded to include "work practice". Work practice is connected to society in the interface between the technical-organisational environment and the social learning environment - which is now expanded and described as "the social and cultural learning environment”. The practice concept contains what actually takes place "in practice", but it also includes practice as a constituting expression of human consciousness and learning.

In the general learning model, which is individually oriented, Illeris (2009) distinguishes between three dimensions: the cognitive dimension; the psychodynamic dimension; and the surroundings/society. The acquisition process of learning takes place between the cognitive and the psychodynamic dimensions, which in their turn interact with society; whereas work identity is found in the tension between the cognitive and emotional dimensions.

The cognitive dimension includes aspects of content and reason, and is linked to what Habermas $(1984,1987)$ describes as "the system"; whereas the psychodynamic dimension covers motivational and emotional aspects, and 
is linked to Habermas's "lifeworld". It is society that provides the conditions for learning. The lifeworld is tied to communicative rationality, and the system to instrumental rationality, and the two are strongly intertwined. Lundvall (1992) relates "instrumental” rationality to the expected outcome of interaction (causeeffect); and "communicative" rationality to intuition, worldviews and other factors related to communication. Habermas's theoretical contribution is often used in the innovation literature; see e.g. Moodysson (2007) and Kalsaas (2011).

Illeris distinguishes between different forms of learning in the cognitive dimension. "Assimilative" learning is described as a general form of learning: it is used in everyday life in the encounter with new impressions and impulses. This is also the most common form of learning in schools, as the students' knowledge is gradually built up over time. "Accommodative" learning is a more demanding form of learning, as it transcends boundaries. In this kind of learning, we cannot immediately understand or relate to what is happening. It requires that existing understandings are overcome or broken down, which in turn requires creative efforts to restructure what is already known, through reflection. This is denoted “relearning” in Kolb’s work. So-called “aha experiences" and a perception that "the pieces have fallen into place" occur in relation to this form of learning. Accommodative learning is crucial in any attempt at introducing improved work practises. "Transformative" learning is the most demanding form of learning examined by Illeris. This is the type of learning we may encounter if we lose our job and have to retrain in order to get a new one, which often means that we have to develop a new worldview or a new basic outlook. This can be perceived as a life crisis on the personal level.
The psychodynamic dimension of learning, with its emotional, intentional and motivational patterns, is influenced by the cognitive dimension, in the shape of our knowledge and skills. For example, so-called "bad chemistry" between individuals can drastically hamper our ability to learn, but if we gain better insight into the work of those we do not initially feel sympathetic towards, such emotions may change. The reasons for defensiveness and resistance to learning are found in the emotional dimension, and Illeris sees the factor of "defending identity" - which is one of several mental defence mechanisms - as crucial in this context. In our working lives we often establish an identity tied to something we master well, and which others also consider us as proficient at. For example, someone may be good at using an advanced control system, PLC controlling, programming, and so on. Strong work identities can easily lead to active resistance to any change which might threaten these identities - such as change that involves an accommodative learning process. According to Illeris, the general tendency for adults is that the more demanding and complicated the learning requirements, the greater the psychodynamic barriers in the shape of defensiveness or resistance. Levin and Klev (2001) point out that learning is often prevented because we wish to avoid situations in which individuals might lose face. This is also a central concern in Argyris's (1990) works. This phenomenon can be linked to the psychodynamic dimension. The overall model is illustrated in Fig. 1.

The best conditions for workplace learning are found in the area where work practice and work identity overlap. It is possible to imagine that if there is no such overlap, individuals might try to modify their work practices in such a way that they become aligned with their work identity, or they might resign and look for work with a different

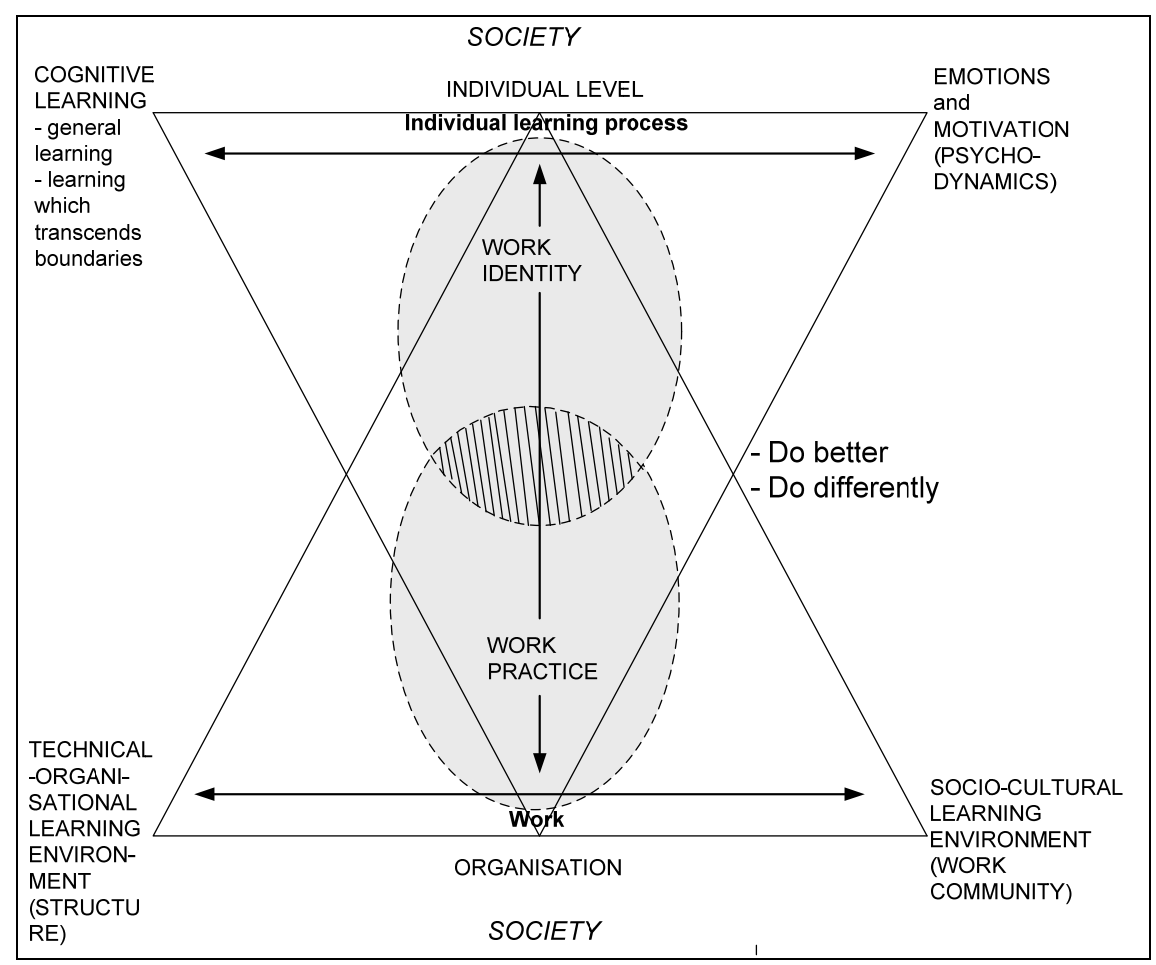

Fig. 1. Workplace learning (Adapted and translated from Illeris (2009)) 


\subsection{Production Control in Lean Construction: The Last Planner System (LPS)}

Koskela and Howell (2002) and Koskela and Ballard (2006) focus on production control when they argue that what they call the scientific experimentation model constitutes the control mode of the LPS. They relate their conceptualisation to Shewhart and Deming (1939): "Let us recall the three steps of control: specification, production, and judgment of quality. [...] In fact these three steps must go in a circle instead of in a straight line [...]. It may be helpful to think of the three steps in the mass production process as steps in the scientific method. In this sense, specification, production, and inspection correspond respectively to making a hypothesis, carrying out an experiment, and testing the hypothesis. These three steps constitute a dynamic scientific process of acquiring knowledge."

Koskela and Ballard (2006) interpret the meaning of this quotation as suggesting that when a performance target has not been met, rather than changing the performance level in order to achieve a predetermined goal, the focus should be on finding the causes for the failure, and on acting on those causes. Note that the value generation perspective in Lean Construction is also founded on the work of Shewhart and Deming; cf. the Transformation-Flow-Value (TFV) model in Koskela (2000).

Furthermore, Koskela and Ballard (2006) contrast the scientific experimentation model to the thermostat model, which is described as the typical mode of production control in conventional production management. They link the thermostat model to the cybernetic model of execution control in management. According to Hofstede (1978), the following properties apply to this model:

- There is a standard for performance

- Performance is measured at the point of output (or input)

- The possible variance between the standard and the measured value is used to correct the process so that the standard can be reached.

According to Koskela and Howell (2002), the thermostat model is identical to the feedback control model as defined in modern control theory (Ogunnaike and Ray, 1994).

\subsection{Learning Loops and Learning Cycles}

Ashby (1960) and Argyris and Schön (1998) distinguish between single-loop and double-loop learning. Single-loop learning can be conceptualised as "Doing Better", and double-loop learning as "Doing Differently". The distinction between these two patterns of learning can also be explained by using the metaphor of a thermostat (Rooke, 2005). The adjustments made by the thermostat in response to changes in temperature illustrate single loop learning, whereas the adjustments made to the thermostat control - determining the range of temperatures maintained by the thermostat - illustrate the workings of the double loop learning process.

It is part of the nature of this difference between double and single loop learning that beginning to do things in a different way is more demanding than pursuing the already established strategy, but with a few adjustments, in terms of the learning involved (in other words, assimilative versus accommodative learning).

Expanding on Ashby (1960), Argyris and Schön (1998) argue that for a company, "doing differently" might require that external resources be brought in to help with the improvement work. Thus, greater competence on grasping via comprehension can be built through action research approaches where academics and researchers cooperate with the company. This relates to the traits considered by March (1999; see below) as limiting the value of experiential learning.

Rooke (2005) relates Kolb’s (1984) experiential learning cycle to Deming's Quality Cycle (Deming, 1986), also widely known as "Plan-Do-Check-Act". "Plan" relates to abstract conceptualisation; "Do" to active experimentation; "Check" to concrete experience; and “Act” to reflective observations. Deming's quality circle, which draws on his joint work with Shewhart from 1939, is, in all its simplicity, widely applied in lean implementations and popular among consultants in the field. However, unlike Kolb’s work (1984), the quality circle does not offer any conceptualisation of learning as such. Rather, it is assumed that learning is likely to take place along the course of the Plan-Do-Check-Act cycle.

\subsection{The Limitations of Experiential Learning}

According to March (1999), learning from experience does not produce perfect results by itself. It has its limitations. Firstly, experiential learning tends to exaggerate the importance of actual events relative to the events that might have occurred, and "thus to be quite sensitive to the rate of experience relative to the change in the world” (p. 332). Secondly, experiential learning tends to close the door on experimentation, according to March. It is fairly easy for a fast learner to fall into a pattern of repeating rewarding behaviour, and to stop reaching for the best possible performance. This can mainly be attributed to the ways in which strategies, competence and aspirations adapt simultaneously. Thirdly, experiential learning is not a good way to learn theories of behaviour. The starting point for March's line of argument is that if behaviour conforming to one theory produces rewards, the other theories will tend to be neglected.

Because of these problems, simple experiential learning in organisations is a flawed process. However, research and consultation can supplement this learning; not by attempting to substitute it but by helping to mitigate the limitations of ordinary and experiential knowledge.

Fujimoto (1999) avoids the problem of the limitations associated with experiential learning by distinguishing between "routinised manufacturing capability" and "routinised learning capability" on the one hand, and "evolutionary learning capability" on the other in his study of learning in the Toyota Company. Evolutionary learning capability, he argues, is a "nonroutine ability that affects creation of the above routine capabilities themselves through irregular processes of multi-path system emergence” (p. 17).

\subsection{Closing in on Learning Theory and Research Questions}

A significant difference between the contributions made by Kolb and Illeris is that Illeris's model captures the learning arenas associated with the technical- 
organisational and socio-cultural environments found in workplaces, whereas such learning conditions are not taken into account in the experiential learning circle. Moreover, unlike Kolb, Illeris also includes individual emotions and motivations as a condition for work identity and thus learning, a level at which an important key to understanding resistance to learning can be found. However, although these factors are not mentioned in Kolb's model, it is apparent from his line of argument and his development of the model - where he argues that adults are different from children - that they are also a consideration for Kolb. Adults are not empty vessels to be filled or clay in need of shaping, he argues. Adults have knowledge, values, relationships and intentions that influence how they behave and how they learn new things. Moreover, resistance to learning can be linked to Kolb's argument that for adults, all learning is relearning since learning is a continuous process based on experience. This follows from the fact that being asked to reject knowledge tied to one's work identity - cf. Illeris - can lead to discomfort and thus generate resistance.

A strong aspect of Kolb's contribution is the insight it provides into how we generically grasp new information via emotions and interpretation of concrete physical conditions and (or) through abstract thinking, and how these forms of are transformed, or processed, into how we make sense of things by means of internal understanding, and (or) used in active experimentation. The impulse of experience gives ideas their impetus.

These aspects are complementary to Illeris's cognitive learning and the different forms of learning, ranging from assimilative learning (which is described as general learning in Figure 1) to accommodative or even transformative learning (described as learning which transcends boundaries). Illeris suggests that the transformative forms of learning require modified behaviour and practice, such as when the LPS is implemented in a company which has practised conventional project management up to this point.

The distinction made by Koskela and Howell (2002) and Koskela and Ballard (2006) between the thermostat model and the scientific experimentation model is debatable. The thermostat model is taken from engineering; translated to the social sphere and organisational development, it is people who assess what the divergence from the expected performance amounts to (such as in the LPS). Furthermore, the model of control is tied to a focus on making controlled adjustments, or "doing better" and the single-loop learning model. One example is when more manpower is added in order to complete building tasks on time.

The scientific experimentation model seems to be based on a positivist scientific ideal of testing hypotheses. This is not entirely unproblematic given that organisational development is a social science concern. With a certain amount of goodwill, however, the model can be interpreted as a metaphor for double-loop learning, i.e. aimed not only at doing things better, but also at doing them differently if necessary - and the authors refer explicitly to root cause analyses as an interesting potential defining feature of what they describe as the scientific experimentation model.

Moreover, the basis for further conceptualisation is related to the specification, production, and inspection found in the mass production process. This process is typically associated with machinery (such as a CNC machine or a stamping machine with tools for shaping a product) and assembly line production. The manufacturing mass production process differs quite considerably from the processes involved in construction work, which are largely based on skilled craftsmanship. Simple transferral of a model from one type of production to another should therefore be viewed with suspicion.

In this context, an understanding of the scientific experimentation model would be that when there is failure to meet the production target, the machines should be adjusted, but potential causes should also be sought in factors such as material quality, temperature, software, tool wear and tear, and so forth. This is probably the most widespread approach within manufacturing, with or without a lean production agenda.

Furthermore, if we take March's points about the limitations of experiential learning into account, it is by no means certain that the control mode provided by the LPS is capable of producing changes which really "make a difference”, for example in terms of identifying new ways of organising the work. Potential measures are framed by the limitations contained in the experiential learning approach; confer Fujimoto's (1999) assertion that evolutionary learning capability helps overcome the limitations of routinised learning.

Should we wish to distance the LPS approach from the conventional control model - and there are many good reasons for doing so - it can be argued that the LPS should be based on both single loop and double loop learning; that both forms are considered equally important for the further analysis; and that the most important practical distinction between conventional production management and the LPS approach is probably the move from a deterministic approach to a non-deterministic philosophy of science. Although this is not necessarily explicitly expressed, it can be argued that this is at the basis of the rejection of the conventional approach to project management - which is to start out with a detailed masterplan, and to believe that given sufficient planning efforts, it constitutes a suitable tool for successful implementation - in favour of starting out with a milestone plan, and gradually increasing the level of detail of the planned activities in close cooperation between different trades as the date of production commencement approaches.

Based on this theoretical review, the further analysis will be guided by the following research questions:

- In what ways can the LPS be expected to alter the learning arenas compared to conventional project management in construction?

- According to learning theory, what are the main challenges associated with implementing the LPS?

- What kind of learning can be linked to an implemented LPS that functions as intended?

\section{Discussion - the Last Planner System and Learning}

In Table 1 we seek to identify some typical differences between repetitive mass production and construction work.

There are great variations within each group included in this table - not least within manufacturing, which 
involves so many types of production, and where even within typical mass production some jobs are not monotonous, for example work that is carried out by electricians and mechanics. And within construction, too, there are many different ways of organising the work which generate more or less variation, even disregarding the LPS. For example, in pursuit of advantages of scale, the work is sometimes organised such that different squads come in and perform the same tasks in one building (or section) after the other. Someone who plasters walls for weeks on end probably becomes very proficient at this task, but may find the work boring after a while, with the result that the strong division of tasks sooner or later becomes counterproductive. Attempts are also made at increasing the industrialisation of the construction process, by increasing the proportion of mounting work of components produced indoors. This development can be expected to generate more jobs characterised by a lack of variation. Examples of trades that may be said to have the most monotonous jobs are painters and roofers. In addition, construction work often means exposure to cold, draughty and wet work environments.

Skorstad (2002) points out that according to working life research, craft-like production is associated with positive working conditions, and our review in Table 1 also shows that a relatively large proportion of jobs within construction achieve a relatively high score on factors associated with good work conditions, namely varied tasks, participation in decision making and possibilities for exerting influence, possibilities for continued learning, and possibilities for social interaction during work hours and beyond (Gustavsen, 2011; Gallie, 2003).

\subsection{The Last Planner System and Changing Learning Arenas}

The LPS is based on extensive involvement and cooperation between trades and across company boundaries in the shape of phase planning, lookahead planning and the weekly workplan procedure. This represents a considerable alteration of the technicalorganisational learning environment compared to conventional project management in that many decisions are transferred from the project manager to multi-trade groups and companies. Thus, many people are exposed to new experiences and opportunities for learning across different trades and disciplines. For example, there are very positive reports about the use of the reverse scheduling process in phase planning, which is known to produce "aha" experiences about cross-trade connections among the participants (Kalsaas et al., 2010). The reverse scheduling process typically generates joint reflections on dependencies between tasks and what must be done in relation to previous work and critical deliveries in order to maintain the progress. In terms of learning theory, this can be linked to grasping via comprehension and abstract conceptualisation, since it builds partly on previous experiences and partly on scrutiny of the provided drawings, which is then transformed into intention via collective reflection. Active experimentation only occurs during the production phase. Between production and phase planning comparable processes have taken place, typically resulting in more and more detailed technical solutions and work packages.

Table 1. The technical-organisational learning environment

\begin{tabular}{|c|c|c|}
\hline $\begin{array}{l}\text { Technical-organizational learning } \\
\text { environment (Illeris, 2009) }\end{array}$ & $\begin{array}{l}\text { Repetitive manufacturing / mass } \\
\text { production }\end{array}$ & Construction work \\
\hline Division of tasks / work & Strong division of tasks / work & $\begin{array}{l}\text { Strong division of tasks and strong specialisation } \\
\text { between trades, but a relatively large number of } \\
\text { tasks within each trade. }\end{array}$ \\
\hline Work content & $\begin{array}{l}\text { Little variation for those workers } \\
\text { who are devoted to work with } \\
\text { machinery }\end{array}$ & $\begin{array}{l}\text { Significant variation within most of the trades. } \\
\text { Craftsmanship. Problem solving. }\end{array}$ \\
\hline Scope for decision making & Relatively limited scope & $\begin{array}{l}\text { Relatively large scope as decisions must be made } \\
\text { about how to proceed, e.g. when drawings are } \\
\text { missing or provide incomplete instructions. }\end{array}$ \\
\hline $\begin{array}{l}\text { Scope for using one's } \\
\text { qualifications }\end{array}$ & Relatively limited scope & $\begin{array}{l}\text { Large scope for problem solving in relation to } \\
\text { other trades in many situations. }\end{array}$ \\
\hline Scope for social interaction & $\begin{array}{l}\text { Relatively limited if the tasks are } \\
\text { tied to operating fixed } \\
\text { machinery. }\end{array}$ & $\begin{array}{l}\text { Considerable scope for social interaction, since } \\
\text { the tasks are not tied to operation of fixed } \\
\text { machinery. }\end{array}$ \\
\hline Work strain & May be considerable & $\begin{array}{l}\text { May be considerable, but greater involvement } \\
\text { could mean that it is more manageable. }\end{array}$ \\
\hline
\end{tabular}


In practical terms, the LPS will contribute to the establishment of new arenas that can be regarded as infrastructures for new learning. The various meetings, for phase planning, lookahead planning, production planning, and perhaps also the stand-up meetings or morning meetings, represent such new or altered arenas. Levin and Klev (2001) emphasise that a basic condition for allowing learning to take place is the creation of meeting places or arenas for social interchange.

We can also expect the increased involvement and cooperation across trades and companies to influence the socio-cultural learning environment in a way that facilitates joint problem solving, and thus - together with the changes in the technical-organisational learning environment - to have an impact on work practices and the shared ideas about "how we do things at this building site". However, we are not suggesting that this will solve all the challenges associated with, for example, the bidding system within conventional construction, for which better solutions are sought through a focus on relational contracts and integrated project delivery (Matthews and Howell, 2005), also known as lean project delivery. This approach represents structural changes which can be expected to reduce the scope for opportunistic behaviour across collaborating companies and create a better basis for mutual trust (Kalsaas, 2011).

Cognitive learning as applied by Illeris reaches beyond the experiential learning concept as such, but with work identity as the central focus in a dialectical relationship between cognitive learning and psychodynamics, we can understand experiential learning as the dominant learning aspect of the model.

But methods of improvement, such as the LPS, can also be taught as part of the collaborative approach pursued by the mother company (e.g. a general contractor) with the overall responsibility for the project. Or such training can be organised as courses, where the learning process is typically assimilative and thus conducive to influencing the motivation for change in the psychodynamic dimension. However, this dimension is closely linked to people's individual histories and personalities, and the LPS as such cannot be expected to have any great impact in the short term. Nevertheless, the pedagogical methods which (in accordance with the LPS thinking) are based on involvement appear to be helpful - at least in the Nordic countries, which is the social context this author knows best. Furthermore, there is also room for learning methods which extend past the boundaries of experiential learning in the cognitive dimension, such as when action research is used in collaboration between companies and external researchers or consultants as part of a changeover process. In such cases, accommodative learning might also be involved.

\subsection{Challenges to Implementing Last Planner According to Learning Theory}

Implementation of the LPS can be interpreted as active experimentation following training and instruction designed to create an understanding of the contents of the LPS approach in order to achieve transformation via intention. During the instruction phase, the lecturer seeks to transfer ideas and to create motivation for trying out the new knowledge. In this case we are talking about the simple, un-threatening and general form of knowledge which we can see as primarily being a matter of the lecturer conveying her abstract conceptualisations, and perhaps also her concrete experiences from implementations of these ideas.

According to Illeris's model, experiential learning in the workplace depends on an overlap between work identity and work practice, and is found in this intersection. Additional learning takes place in relation to other life arenas through discussions, the reading of newspapers during break times etc., but the learning tied to the tasks, which is required in order to generate change, takes place in the overlap between work identity and work practice. Thus, when we alter or change the work practices, the success of this changeover depends on it being integrated into the employees' work identity, influence over which is sought through teaching. On the other hand, this type of change also opens up new career opportunities and creates scope for developing new work identities suited to the changes in the desired work practice.

In this author's experiences related to implementation of the LPS, statements along the lines of "this is something we have always done" are quite common (Kalsaas et al., 2010). What we can assume lies behind such statements is that in practice, the conventional method for project management has rarely functioned as construed by the authors who are critical of the method and the underlying, often implicit, theory, and who wish to replace it with something different. In practice, collaboration across trades and mutual problem solving is necessary in order to complete a joint project at all, but this is largely a matter of ad hoc cooperation and may appear confined to fire-fighting in comparison with the LPS. Kalsaas and Sacks (2011) discussed this issue in relation to different types of interdependency between tasks. They found that neither conventional project management nor the LPS incorporated the institutionalisation of the strongest form of interdependency, namely reciprocal interdependency, but that it is nevertheless dealt with in practice. Experienced people know what needs to be done, but the measures do tend to take the shape of fire-fighting when the theoretical implications of such phenomena are not grasped. It should also be mentioned here that in conventional project management it is common to have a structure of fixed progress meetings across trades, and planning meetings aimed at reducing insecurities and risks related to the actual production - the active experimentation.

What distinguishes the LPS radically from conventional project management is that the former moves away from a deterministic perspective on the world towards a non-deterministic philosophy of science as discussed above. Communicating such a changeover of philosophy is not a straightforward undertaking on a building site. Therefore, during the first encounters with this method, it may be perceived as differing very little from conventional project management until those affected experience its impact through involvement and learning by doing.

Experiences from implementation of the LPS also include "aha" experiences. For example (Kalsaas et al., 2010), in one case a foreman confided after several months' efforts to align work practices with the LPS that in the beginning, he did not see that it would make much of a difference, but that it might be worth trying. However, after having tried the LPS in practice, he had become an avid enthusiast of this approach. Confucius, the Chinese 
philosopher, probably captures the core of this learning experience with his well-known words: "Tell me, and I will forget. Show me, and I may remember. Involve me, and I will understand”. With reference to Kolb (1984), we can interpret Confucius's point about involvement as support for the view that deeper learning is achieved through the experiential learning circle.

Based on this discussion, we can assume that for most employees involved in a construction project, only minor changes to work identity are needed to create successful adoption of LPS work practices. However, variations can be found depending on who is the Last Planner in different implementations of the LPS. In early implementations, the team leaders are usually given this role, but more recently, the workmen tend to be defined as the last planners. For example, the workmen are defined as the last planners by the general contractor Veidekke Entreprenør in Norway. Especially when the latter is the case, the employees and workmen who are doing the actual building will experience a greater demand for their knowledge and advice - that is, for their involvement. Many will tend to see this as an enrichment of their work identity and as a factor that improves their work satisfaction, but this is not necessarily the case for everyone. Some may have resigned themselves the being told what to do, or they come from cultures that are more hierarchical than, for example, the Nordic countries, where a different work practice and socio-cultural learning environment is dominant. Due to the same reason, we can expect regional and national differences to exist in terms of the conditions for implementing the LPS. It may therefore take some time before everyone finds it natural and desirable to participate in a development where they have to become more involved. If we take a long-term perspective, this is also an argument for incorporating this work practice into the vocational training for trades in the construction sector. One factor which may contribute to the reservations some people have against greater involvement is that it is accompanied by greater responsibility, and thus perhaps also associated with a perception of greater risk.

The project manager has a key role in the implementation of the LPS, and in relation to implementing major changes in general. This is due to the very great influence he has on each construction project, as well as to the great degree of autonomy he enjoys in relation to the construction company he is employed by with regard to daily operations. On the actual project, his role can be compared to that of a company CEO / Managing Director. Any attempt to implement the LPS in cases where the project manager is not motivated for this approach is therefore a futile undertaking. The same can be said to apply to everyone involved in a construction project in the capacity of a management role, such as foremen and team leaders, albeit to a somewhat lesser degree.

In order for the technical-organisational changes to the learning environment associated with successful implementation of the LPS to take effect, the management level must therefore be fully behind the development. The project manager will have to reduce his own power by delegating decisions to the team of involved parties, including trades represented by other companies. Thus the modifications to the individual work identity required by the manager on such projects are greater than those required by anybody else, as he has to transfer some of the authority of making management decisions onto others. Note that this corresponds to the experiences identified by an experienced professional in the field employed by the general contractor Veidekke Entreprenør, where the LPS has been used over several years, that the craftsmen are more open to changing their work practices than employees from project management. The benefits are that the construction process can be expected to become more predictable, and that there is likely to be a reduction in the resource requirements - the latter stemming, among other things, from the fact that less time will need to be spent on solving acute problems arising along the way (firefighting).

The construction workers' trade union(s) may in some cases take a proactive role in the implementation of the LPS, as has been the case in Norway. The rationale behind embracing the LPS is the involvement aspect, as well as the methods used in the approach. These methods lead to greater predictability and a more rational production process, enabling the members to make more money out of piecework contracts, or to work at a slower pace for the same wages. The LPS can also be expected to reduce the workplace stress associated with handovers and with regard to fire-fighting in general. These factors can help increase workplace satisfaction within the construction sector.

\subsection{The Kind of Learning Linked to The Last Planner System}

It is quite apparent that the learning produced in a wellfunctioning LPS is linked to the pattern which includes a loop of evaluating or re-examining the production plan in terms of what was implemented and what was not, and, not least, with regard to the causes for failure to meet the planned targets. Note that an evaluation mechanism based on the PPC logic has also been developed for the lookahead plan (Ballard, 1997), but it has not been implemented to any considerable degree (Koskela and Ballard, 2006a). Koskela and Howell (2002) and Koskela and Ballard (2006, 2006b) regard this as a control mechanism.

It is a fairly common approach to use the method of " $5 \times$ why" to identify the so-called root cause as to why tasks included in the production plan were not carried out. A PPC of one hundred percent is not likely in this sector over time unless the planning is manipulated to make it happen; although it can also occur as a result of lacking pressure on the production apparatus.

There is reason to ask what kind of learning is contained in the " $5 \times$ why" approach. Is it really a method of scientific experimentation, as indirectly argued by Koskela and Ballard (2006)? The following exemplifies the " $5 \times$ why" approach: The roofers failed to turn up as planned in week " $x$ " to start laying the roof. Why? The carpenters did not finish, thus preventing the roofers from commencing their work. Why? They were short of materials (or two men were off sick, or snowfall prevented them from working). Why were they short of materials? The foreman was late placing the order, and the delivery time is several days. Why was he late placing the order? The squad leader had forgotten to inform him that they were likely to run out of materials. And so on.

If we think in terms of testing hypotheses, the hypothesis here is that the roofers will start their work in 
week " $x$ ", and perform a certain volume of work. The " $5 \times$ why" method helps us identify the root cause for this failing to happen; that is, for why the hypothesis was not confirmed.

But so far, only assimilative learning is involved. An obvious adjustment would be that the team leader would from now on avoid making such mistakes, now that everyone can see that he was the one not taking seriously enough his routines for ensuring that the materials needed by his team are available. In this sense, the difference between this approach and a thermostat model or scientific experimentation is negligible. In many climates, rooflaying is a critical activity as it is crucial that the building is watertight. A delay here can easily extend the construction period, although there is reason to believe that the underlying causes would also be identified by using the thermostat model, albeit probably with a less routinised systematic approach. How else would adjustments be made? The intention with this is not to suggest that no differences exist between conventional project management and the LPS; rather, it is to emphasise that the differences between the thermostat model and the scientific experimentation model may be of limited value in terms of explaining these differences.

If we look at the example of the " $5 \times$ why" method above in relation to single and double loop learning, we are dealing with single-loop learning and "doing better" if the team leader adjusts his future awareness and behaviour in order to avoid repeating such blunders. On the other hand, if the method leads to a review of the project routines, and development of these - for example in the shape of new checklists for critical tasks - we are dealing with "doing differently" and double-loop learning, even if this is based on fairly unthreatening assimilative learning generating new active experimentation. However, a dilemma is contained in the organisation of the project, as it is per se of a temporarily confined nature. Because of this, the incentives for structural changes to the technicalorganisational learning environment are limited (Mintzberg, 1993). Furthermore, the fact that the project management is also very autonomous in relation to the mother company represents another structural limitation on innovation and "doing differently". The LPS can therefore be expected primarily to generate single-loop learning and very limited forms of double-loop learning. However, this does exclude the possibility that the LPS helps raise many important questions, and that the active use of " $5 \times$ why" contributes to shedding light on hidden problems. These conditions tied to limitations in the motivation for innovative thinking within the structure of project production can be regarded as part of the technicalorganisational learning environment in Illeris's model as applied to the construction sector.

In order to generate a more complex form of doubleloop learning, and accommodative learning that necessitates, for example, a new approach to the division of labour, introduction of the LPS, and relational contracts (such as integrated project delivery), the mother company probably needs to play an active role in encouraging change, with or without input from external resources applying an action research perspective; confer the distinction made by Fujimoto (1999) between "routinised learning capability" and "evolutionary learning capability". In addition to the implications of the structure surrounding project organisation, such a conclusion is also based on the limitations associated with experiential learning pointed out by March (1999).

\section{Conclusions}

The theoretically informed analysis of the LPS shows that its implementation has a particular impact on the technical-organisational learning environment, influencing it in a direction that can be seen as advantageous in that it promotes conditions which are associated with job satisfaction. Thus, it can also be expected to create a positive spin-off effect with regard to the socio-cultural learning environment, through the creation of a series of new meeting arenas of great importance for reflection and experiential learning.

Based on learning theory, the main challenge associated with implementing the LPS is to ensure that the work identity of employees alters in a way that matches the desired work practice. Resistance to change can be traced to the psycho-dynamic dimension, where our emotions are found. The other dimension of work identity is more easily modified by offering the optimal learning method, but learning that transcends boundaries and requires modified practices on the individual level are closely linked to the emotional dimension with regard to the prospects for success. Thus, seeking to implement the LPS, and other major changes in general, is a futile exercise unless key personnel in the project management are positive to such a move. On the other hand, major changes, such as those represented by the introduction of the LPS also create conditions which allow new work identities to be developed. In terms of cognitive learning, generating accommodative learning through assimilative learning alone - by offering manuals and courses appears to be too weak an approach to overcome resistance. Based on the input from learning theory, a considerably more efficient approach is to draw on additional resources from the company in question, or to hire in external consultants, or to invite researchers to work on projects in collaboration with the ordinary project staff during an alteration phase, based on an action research perspective. Such an approach also has the potential of overcoming the inherent limitations of experiential learning.

When the LPS is practised as intended, it produces an experiential learning cycle. This requires an active approach to evaluation plans by those involved in the project in order to uncover underlying reasons for failure to complete tasks as planned - and it also depends on this knowledge being shared on the same arena. The type of learning embedded in this structure is identified to be primarily of the single-loop type, as well as to include basic, unthreatening forms of double-loop learning. For instance, it is difficult to generate changes to the organisation of the engineering and architectural work based on this learning. The limited scope for learning is attributed to the limitations associated with experiential learning, as well as to the structure governing projectbased production, with its short-term perspective of the time-span of the current project.

With regard to theoretical implications, understanding the learning which takes place particularly within architectural and engineering work is shown to depend on an experiential cycle whose contents are limited to reflective observation and abstract conceptualisation for major aspects of the learning process. Furthermore, the 
conceptualisation which links conventional production control to the thermostat model and the LPS to the scientific experimentation model is identified as highly debatable and too simplistic. Finally, an attempt has been made to demonstrate how approaching the LPS on the basis of learning theory can help implement the system in practice and maximise the learning effects that can be derived from it. This requires, among other things, an appreciation of its limitations and an awareness of at what points additional measures must be activated in order to successfully achieve learning that transcends boundaries.

\section{References}

Argyris, C. (1990). Overcoming Organizational Defences: Faciltating Organizational Learning. Englewood Cliffs, New Jersey: Prentice Hall.

Argyris, C. and Schön, D. (1998). Organizational learning II. Theory, Method,and Practice. New York: Addison-Wesley Publishing Company.

Ashby, W. R. (1960). Design for a Brain. New York: John Wiley.

Ballard, G. (1997). Lookahead Planning. Proceedings from the 5th Annual Conference of the International Group for Lean Construction, Gold Coast, Australia: Griffith University.

Brodetskaia, I., Sacks, R.,and Shapira, A. (2011). A Workflow Model for Finishing Works in Building Construction. Construction Management and Economics (under review).

Deming, W. E. (1986). Out of the Crisis: Quality, productivity and competitive position. Cambridge: Cambridge University Press.

Dewey, J. (1910). How we Think. New York: D. C. Health.

Dewey, J. (1934). Art as Experience. New York: G. P. Putnam, Capricorn Books.

Dewey, J. (1938). Experience and Education. Kappa Delta Pi.

Dewey, J. (1958). Experience and Nature. New York: Dover Publications.

Elden, M. and Levin, M. (1991). Cogenerative learning. Bringing participation into action. In W. F. Whyte (ed.), Participatory action research. London: Sage.

Fujimoto, T. (1999). The Evolution of a Manufacturing System at Toyota. New York: Oxford University Press.

Gallie, D. (2003). The Quality of Working Life: Is Scandinavia Different? European Sociological Review, 19(1), 61-79.

Gustavsen, B. (2011). The Nordic Model of Work Organisation. Journal of the Knowledge Economy, 2( 4) (Accepted).

Habermas, J. (1984). The Theory of Communicative Action, 1. Reason and the Rationalization of Society. Boston, MA: Beacon Press.

Habermas, J. (1987). The Theory of Communicative Action, 2. Lifeworld and System: A Critique of Functionalist Reason. Boston, MA: Beacon Press.

Hofstede, G. (1978). The Poverty of Management Control Philosophy. Academy of Management Review, 450461.

Howell, G., Macomber, H., Koskela, L., and Draper, J. (2004). Leadership and Project Management: Time for a Shift from Fayol to Flores. Proceedings of IGLC12, LO-School, Elsinore, Denmark.

Illeris, K. (2009). Læring i arbeidslivet. Denmark: Learning Lab Denmark, Roskilde Universitetsforlag.
Jørgensen, C. H. and Warring, N. (1992). Læring på arbeidsplassen. In K. Illeris (ed.) Udspill om lcering $i$ arbeidslivet. København: Roskilde Universitetsforlag.

Kalsaas, B. T. (2011). Business interaction and knowledge creation illustrated by a supply chain from the offshore oil- and gas industry. Forthcoming in The IMP Journal, 5( 2).

Kalsaas, B. T. and Jakobsen, R. (2009). Forbedringsarbeid i Hydros produksjon av bilkomponenter for å oppnå bedre materialflyt basert på “lean” produksjonstenkning. In B. T. Kalsaas (ed.), Ledelse av verdikjeder. Strategi, design og konkurranseevne. Trondheim: Tapir Akademisk Forlag, 215-236.

Kalsaas, B. T., Skaar, J.,and Thorstensen, R. T. (2010). System og resultater fra utprøving av planleggingsmetoden "Last Planner" (Lean Construction) på Havlimyra oppvekstsenter i Kristiansand commune. Byggkostprogrammet, University of Agder and Skanska Region Agder, Grimstad.

Ko, C. H., Wang, W. C., and Kuo, J. D. (2011). Improving Formwork Engineering Using the Toyota Way. Journal of Engineering, Project, and Production Management, 1(1), 13-27.

Kalsaas, B. T. and Sacks, R. (2011). Conceptualization of Interdependency and Coordination between Construction Tasks. Draft submitted to IGLC 19 Lima.

Kolb, D. A. (1984). Experiential learning. Experience as the source of learning and development. Englewood Cliffs, New Jersey: Prentice Hall.

Koskela, L. (2000). An exploration towards a production theory and its application to construction. VTT publications 408, VTT Building Technology, Technical research centre of Finland.

Koskela, L. and Howell, G. (2002). The underlying theory of project management is obsolete. In D. P. Slevin, D. I. Cleveland and J. K. Pinto (eds.), PMI Research Conference, Seattle, WA: Project Management Institute, 293-302.

Koskela, L. and Ballard, G. (2006a). What is Lean Construction - 2006. Proceedings of Construction in the XXI Century: Local and global challenges, ARTEC, Rome.

Koskela, L. and Ballard, G. (2006b). Should project management be based on theories of economics or production?, Building Research \& Information, 34(2), 154-63.

Koskela, L., Stratton, R.,and Koskenvesa, A. (2010). Last Planner and Critical Chain in Construction Management: Comparative Analysis, Proceedings of the 18th Annual Conference of the International Group for Lean Construction IGLC 18, K. Walsh and T. Alves (eds.), Technion - Israel Institute of Technology, Haifa, Israel, 538-547.

Levin, M. and Klev, R. (2001). Forandring som praksis. Læring og utvikling i organisasjoner. Trondheim: Fagbokforlaget.

Lewin, K. (1951). Field Theories in Social Sciences. New York: Harper \& Row.

Lundvall, B.-Å. (1992). Introduction. In B.-Å. Lundvall (ed.), National Systems of Innovation. London: Pinter Publishers, 1-19.

Macomber, H., Howell, G. A. and Reed, D. (2005). Managing promises with the last planner system: Closing in on uninterrupted flow. Proceedings IGLC13, Sydney, Australia. 
Macomber, H. and Howell, G. A. (2003). Linguistic action: Contributing to the theory of lean construction. Proceedings IGLC-11, Blacksburg, Virginia, USA.

March, J. G. (1999). The Pursuit of Organizational Intelligence. Cambridge, MA: Blackwell.

Matthews, O. and Howell, G. (2005). Integrated Project Delivery: An Example of Relational Contracting. Lean Construction Journal, (2), 1.

Mintzberg, H. (1993). Structure in fives: Designing effective organizations. Englewood Cliffs, NJ: Prentice-Hall, Inc.

Moodysson, J. (2007). Principles and practice of knowledge interaction: an in-depth analysis of biotechnology innovation processes. In J. Moodysson, Sites and Modes of Knowledge Creation. On the Spatial Organization of Biotechnology Innovation. Doctoral Dissertation, Lund University, Lund.

Ogunnaike, B. A. and Ray, H. W. (1994). Process Dynamics, Modeling, and Control. Oxford: University Press.

Piaget, J. (1951). Play, Dreams and Imitation in Childhood. New York: W. W. Norton.

Piaget, J. (1968). Structuralism. New York: Harper Torchbooks.

Piaget, J. (1970a). Genetic Epistemology, New York: Columbia University Press.

Piaget, J. (1970b). The Place of the Sciences of Man in the System of Sciences. New York: Harper Torchbooks.

Piaget, J. (1971). Psychology and Epistemology. Harmondsworth: Penguin Books.

Piaget, J. (1978). What is Psychology?, American Psychologist, 648-52.

Shewhart, W. A. and Deming, W. E. (1939). Statistical Method from the viewpoint of Quality Control. Washington, D. C.: The Graduate School, the Department of Agriculture.

Skorstad, E. (2002). Organisasjonsformer. Oslo: Gyldendal.

Smith, N. J., Kolb, D. M.,and David, A. (1986). The User's Guide for the Learning-Style Inventory: A Manual for Teachers and Trainers. Boston, MA: McBer \& Company.

Yin, R. K. (1989). Case Study Research. Design and Methods. (Revised edition). Applied Social Research Methods Series, 5, London: SAGE.

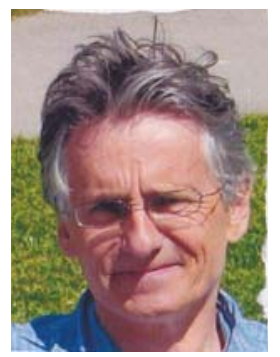

Bo Terje Kalsaas is associate professor of Industrial management at the University of Agder, where he works in the Faculty of Economy and Social research, Department of working life and innovation, at the Grimstad campus. He received his Dr Ing degree (PhD) from the Norwegian Institute of Technology. He has previously been employed by the Norwegian University of Science and Technology, and has been a visiting researcher at the Technion - Israel Institute of Technology (Construction management). His research interests, teaching and publications are concentrated in the areas of supply chain management, business to business relationships, lean production, lean construction, and workplace learning, knowledge development and innovation. Kalsaas is member of the IMP group and the Lean Construction Institute. 